\title{
Minimizing Flute Engagement to Adjust Tool Orientation for Reducing Surface Errors in Five-Axis Ball End Milling Operations \\ DOI:
}

10.1115/1.4048267

\section{Document Version}

Accepted author manuscript

Link to publication record in Manchester Research Explorer

Citation for published version (APA):

Habibi, M., Kilic, Z. M., \& Altintas, Y. (2020). Minimizing Flute Engagement to Adjust Tool Orientation for Reducing Surface Errors in Five-Axis Ball End Milling Operations. Journal of Manufacturing Science and Engineering, 143(2). https://doi.org/10.1115/1.4048267

\section{Published in:}

Journal of Manufacturing Science and Engineering

\section{Citing this paper}

Please note that where the full-text provided on Manchester Research Explorer is the Author Accepted Manuscript or Proof version this may differ from the final Published version. If citing, it is advised that you check and use the publisher's definitive version.

\section{General rights}

Copyright and moral rights for the publications made accessible in the Research Explorer are retained by the authors and/or other copyright owners and it is a condition of accessing publications that users recognise and abide by the legal requirements associated with these rights.

\section{Takedown policy}

If you believe that this document breaches copyright please refer to the University of Manchester's Takedown Procedures [http://man.ac.uk/04Y6Bo] or contact uml.scholarlycommunications@manchester.ac.uk providing relevant details, so we can investigate your claim.

\section{OPEN ACCESS}




\title{
Minimizing flute engagement to adjust tool orientation for reducing surface errors in five-axis ball end milling operations
}

\author{
M. Habibi ${ }^{1 *}$, Z.M. Kilic ${ }^{2}$, Y. Altintas ${ }^{1}$ \\ ${ }^{1}$ Manufacturing Automation Laboratory, Department of Mechanical Engineering, The University of British Columbia, 2054-6250 Applied Science, \\ Lane Vancouver, BC V6T 1Z4, Canada. \\ ${ }^{2}$ Department of Mechanical, Aerospace \& Civil Engineering, The University of Manchester, Oxford Rd, Manchester, M13 9PL, UK. \\ *Corresponding author, email: mohsen.habibi@ubc.ca
}

\begin{abstract}
Surface errors due to force induced tool and workpiece deflections are one of the major errors in multi-axis machining of parts especially with thin walled structures. Dominant approaches to reduce these surface errors are re-machining the part, feed scheduling and tool path modification. These methods are time consuming and computationally costly and they rely on experimental data which is used in cutting force and deflection predictions. The present paper introduces a pure geometrical approach to reduce surface errors drastically by minimizing the engagement lengths of flutes' cutting edges when a point on the flute's cutting edge is in contact with the design surface. The total engagement length of the flutes' cutting edges when one of them generates a contact point on the workpiece surface is formulated and considered as the minimization objective function of an optimization problem. Tilt and lead angles, which define the tool orientation, are the design variables of the optimization problem subjected to constraints based on the geometrical requirements of the ball end milling process. The optimization problem uses the nominal tool path to generate an optimal tool path with adjusted
\end{abstract}


tool orientations. The presented method is computationally inexpensive and does not need any experimentally calibrated coefficients to predict cutting forces because of the pure geometrical nature of the approach. The method is experimentally validated through five-axis ball end milling experiments in which more than $90 \%$ surface error reduction is achieved.

\section{Keywords}

Ball end milling, surface error, error compensation, flute engagement.

\section{Nomenclature}

i

Cutter location index

$i_{f}$ Last cutter location

WCS, TCS, ECS workpiece, tool and engagement coordinate systems

$, \mathrm{W}, \mathrm{T}, \mathrm{E}$ parameters' subscriptions to represent them in WCS, TCS and ECS

d $,{ }^{*}, \mathrm{P}$ parameters' superscriptions to refer to design variables, solutions and projections

CWE Cutter workpiece engagement

$x_{w}, y_{w}, z_{w}$ Axes of WCS in WCS

$\mathbf{X}_{T}, \mathbf{Y}_{\mathbf{T}}, \mathbf{z}_{\mathbf{T}}$ Axes of TCS in WCS

$X_{E}, Y_{E}, Z_{E}$ Axes of ECS in WCS

$\mathrm{CL}_{i}$

$i^{\text {th }}$ cutter location (tool tip)

$\mathrm{CC}_{i}$

$i^{\text {th }}$ cutter contact point

$\mathbf{C T}_{i}$

$i^{\text {th }}$ ball center point

CC trajectory curve of $\mathbf{C C}_{i}$ 


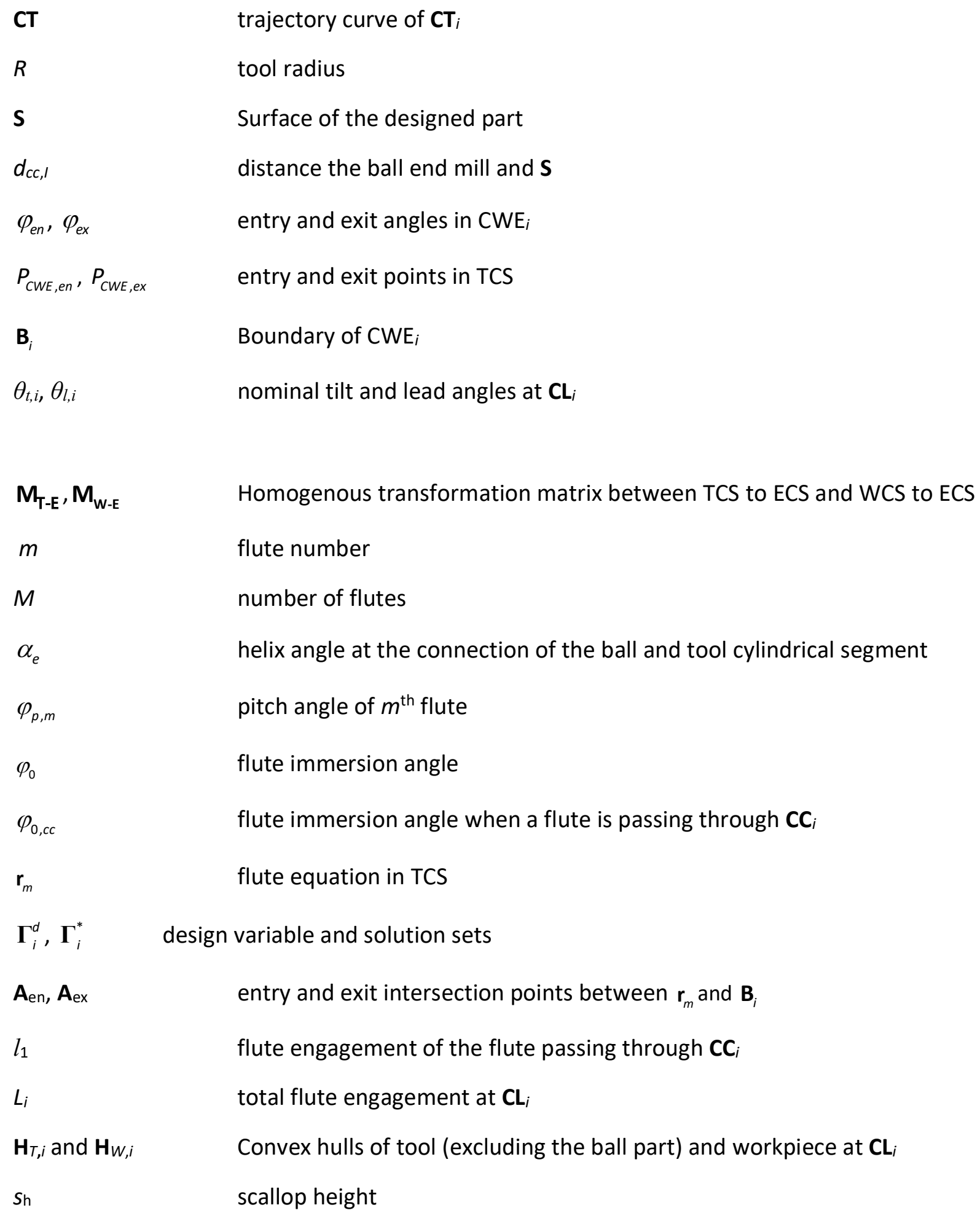




\section{Introduction}

Tool and workpiece deflections are important error sources in multi-axis ball end milling operations especially for slender parts such as turbine and compressor blades and, in general, airfoils. The dominant approach in industry to eliminate geometric surface errors due to deflections is to re-machine the workpiece a few times in which after each time the geometric surface errors are measured and compared with the acceptable tolerances of the designed part. If the surface error did not satisfy the part tolerance bandwidth, the next round of machining would be conducted by numerical controlled (NC) codes modified by the measured errors. This process continues until the measured geometric surface errors fall within the tolerance bandwidth, which is a time consuming and costly trial and error based process to plan ball end milling of airfoils.

The dominant approaches in academic research to eliminate deflection induced geometric surface errors are based on calculating cutting forces and finding force induced deflections and their effects on the geometric surface errors. Feed scheduling and tool path modification [1] are the most heavily invested methods among researchers. However, these methods are computationally expensive because they require the prediction of cutting forces and static deflections. For cutting force prediction, Finite Element Analysis (FEA) $[2,3]$ or semi-analytical approach $[4,5]$ is common among research communities. Both approaches rely extensively on the experimentally identified coefficients, for example Johnson-Cook's constants for FEA approach [6] or orthogonal cutting force coefficients [7] for semi-analytical approach, which are cumbersome to obtain for wide range of materials. In addition, NC codes especially in ball end milling of complex geometries consists of many cutter locations, in most industrial cases tens of 
thousands of lines. Applying FEA analysis for cutter locations along the tool path is dramatically computationally expensive in scale of hours for a part with average size. In the present paper, a pure geometrical approach to reduce the geometric surface errors is introduced in which the need for cutting force and deflection calculations are circumvented for the tool path modification.

The Mirror method [8] is the most popular approach to modify tool path in order to reduce the geometric surface errors by changing the tool positions. The method pushes the tool toward the workpiece in an iterative scheme until the calculated surface error falls in the tolerance bandwidth. The method relies solely on the cutting force and surface error prediction, which is computationally expensive with uncertainties in the model parameters. In addition, since the Cutter Workpiece Engagement (CWE) needs to be updated due to the tool position change at each iteration of the mirror method, the computational time is further increased. CWE is an inprocess contact area of the tool envelope with the in-process workpiece during machining. In ball end milling processes, CWE lies on the spherical portion of the tool. The geometric surface errors in flank milling processes are compensated using the mirror method by Habibi et al. [9] and Soori et al. [10]. The mirror method and feed scheduling are used by Wan et al. [11] in peripheral milling of the thin walls. The geometric surface errors are compensated by Chen et al. [12] for multilayer milling and finishing operations. Ma et al. [13] modified the ball end position and orientation based on the mirror method. The ball end mill deflection error compensation in z-level contouring strategy is conducted by Wei et al. [14] without considering the workpiece deflection. The surface error is compensated in flat end milling of tubular parts using the mirror method by Bera et al. [15] which is not applicable to ball-end milling of free form surfaces. An FEA method 
is proposed by Ratchev et al. [16] for surface error prediction and compensation in flat end milling which is computationally expensive. CWE is not updated in the mentioned works.

Tool orientation adjustments in ball end milling has been the topic of less research works on reducing the geometric surface errors than the tool position change. Most research works investigated the tool orientation effects on the form error, surface topography and chatter stability in ball end milling. A method for chatter avoidance by tool orientation adjustment is proposed by Chao and Altintas [16] without surface error consideration. The effects of tool orientation on chatter stability, cutting forces and geometric surface errors in five-axis ball end milling are investigated by Ozturk et al. [17] without considering the surface error compensation. The effects of the tool orientation on the surface topography is investigated by Layegh et al. [18]. Layegh et al. [19] investigated the tool orientation change on flexible part deflection. However, they considered overall deflection at the top of the part and not at the cutter contact point. Habibi et al. [20] proposed a two-module algorithm considering CWE update at every iterations of the mirror method for five-axis ball end milling. The first module is changing the tool orientations based on cutting forces and surface error prediction along the tool path. The second module changes the tool positions based on the mirror method [21] for the cutter locations in which after the first module still experiences unacceptable surface error. Although the presented method is faster than applying the mirror method to all cutter locations, it is still computationally expensive in terms of cutting force and surface error calculations, especially in the second module. One of the main challenges in mechanics based deflection and compensation methods is the uncertainties in material's cutting force coefficients and stiffness of tool and the part which are the main sources of prediction errors [21]. 
In a ball end milling process, the tool path is generated by a CAM software in such a way that the tool's ball (spherical) part is tangent to the desired or designed surface. The result of this tangency is a set of cutting edge contact points on the desired surface. Only these contact points generate the desired surface. In down-milling operations, the chip thickness is zero at the cutting edge point that is in contact with the designed surface, hence the contribution of this point to cutting force is zero. However, if the remaining points on the cutting edge are not in contact with the desired surface, they will remove chip due to helix angle, engagement conditions and tool axis orientation. As a result, they will generate cutting force acting on the entire tool/blade structure and will cause deflections at the contact points generating the desired finish surface. The deflection effects of cutting edge points which are not on the design surface are removed by the following flute's cutting edge hence they do not contribute to the deflection errors imprinted on the finished surface.

Based on the understanding of ball end milling kinematics, chip and force generation explained above, this paper introduces a new, completely geometry-based approach to minimize the surface errors by trying to keep the flute's cutting edge out of cut while the contact point CC is in contact with the design surface. This condition will minimize the instantaneous chip thickness hence the cutting force momentarily, leading to minimum deflection at the surface contact point CC. Since the CWE zone is very small in finish machining, usually only one flute is in cut and a small adjustment of tool's lead and tilt angles can achieve this objective, and may even reduce the force to zero depending on the CWE area and tool axis orientation limits which are imposed by the interference of tool shank with the part. The proposed method introduces a pure geometric approach that is computationally fast and accurate in reducing the surface error 
without knowing the tool deflection or cutting forces. The tool path must be planned to have chatter-free machining before applying for any surface error compensation. Machining with chatter would produce a damaged part with a very rough surface, hence the depths of cut and spindle speeds along the tool path must be planned in accordance with the chatter stability lobesas practiced in industry [21].

The paper is organized as follows: The concept of the proposed idea in the paper is presented in Section 2. The geometry of the ball end milling process needed for the tool orientation adjustment is described and required coordinate systems are constructed in Section 3. The minimization problem and its constraints are described in Section 4. In Section 5, the proposed method is experimentally validated in a five-axis ball end milling process. Section 6 concludes the paper.

\section{Core concept of surface error reduction by flute engagement minimization}

Fig. 1a shows the overall work flow of the surface error compensation methods based on the interaction with the cutting process and structural flexibilities of part and tool as reviewed in Section 1 . These physics-based models are very important to understand the highly complex ball end milling of airfoils, and the factors which affect the forced and chatter vibrations, contouring errors induced by servo drives and static deflection errors left on the desined surface. Any uncertainty in the cutting force coefficients, and the stiffness of part and the tool will automatically lead to prediction errors. 
(a)

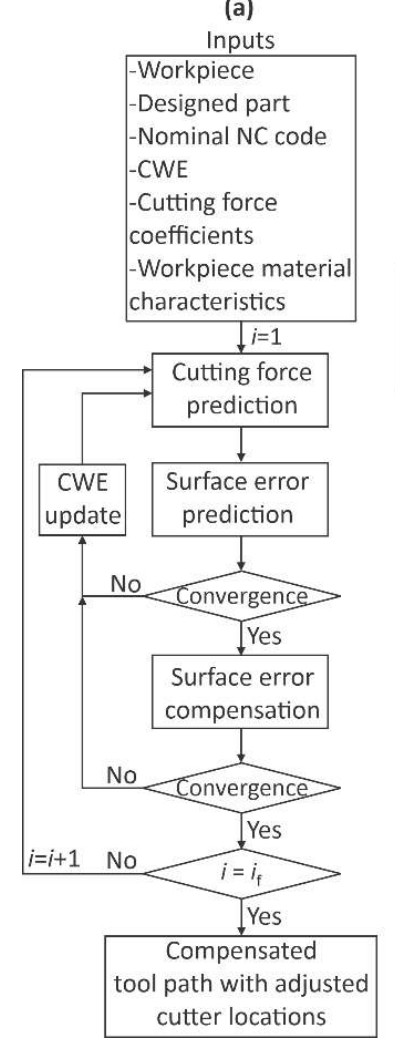

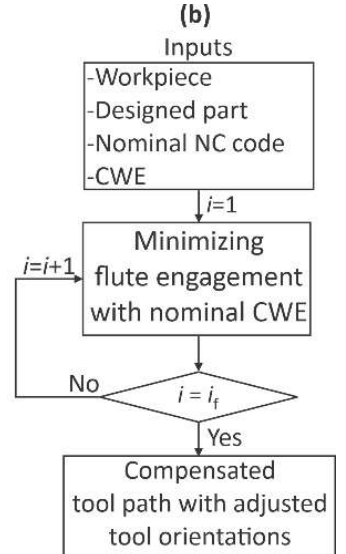

tool orientations

Fig. 1. Surface error compensation paradigms: a) The most common approach based on cutting force, deflection and surface error predictions, b) the presented approach based on flute engagement minimization.

Based on the principles learned from the physics-based ball end milling process $[20,21]$, this paper introduces a new but completely geometry-based method to minimize the deflection errors as shown in Fig. 1b. Ball end milling tool path consists of cutter locations, CL (tool tip coordinates), and corresponding tool orientation vectors, $\mathbf{z}_{\mathrm{T}}$. The chip thickness generated by any point on the flute's cutting edge is $h(\phi)=c \sin \phi$ where $\phi$ is the immersion angle measured clockwise from the surface normal. The differential cutting force with an infinitesimal flute height $d z$ in cut with material and tool geometry dependent cutting force coefficient $K_{c}$ is $d F(\phi)=K_{c} h(\phi) d z$. By integrating the differential forces generated by all cutting edge points in 
Cutter Workpiece Engagement (CWE) zone, the cutting forces acting on the part and tool can be predicted [21]. For a given cutter location and tool orientation, the ball part of the tool is tangent to the designed part at a point called cutter contact point (CC). The desired surface is created when the flute's cutting edge generates this point on the workpiece where the immersion is $\phi=0$ and the chip thicknes is zero. Due to the relative topology of the cutter location, tool orientation with respect to the CWE and helix angle of the flute, the remaining points on the cutting edge maybe engaged with CWE and remove the material with non-zero chip thickness. While the cutting edge in contact with the point on the designed surface (CC) generates zero force, the remaining part of the flutes engaged with the material generates force that deflects the tool at CC. The idea behind the present paper is to adjust the tool axis orientation geometry in such a way that when any point (CC) on the flute's edge is in contact with the desired surface, the remaining points on the cutting edge of the same flute are kept outside CWE (cutting) zone to generate zero chip $(h=0)$ and zero force $(F=0)$, hence zero deflection at CC. As soon as the tool rotates away from this point, the flute's edge starts cutting material, generating force hence causing deflections. However, these deflection effects are no longer left on the designed surface and they are removed by the following flute's cutting edge. The adjustment of the tool axis orientation must not violate the airfoil tolerance by interfering with its other parts or neighboring blades in impellers and blisks. Also, if the engagement zone (CWE) is large, the second flute may be in cutting zone as well which limits the reduction of force to zero. If the trajectory of the center of the ball part of the end mill is kept the same, changing the tool orientation only causes the ball (spherical) part of the tool to be rotated around the ball center by considering the interference and multiple - flute engagement. In this way, CWEs along the tool path would not 
be changed or updated. Therefore, with given CWE data, tool orientations can be adjusted without the need for regenerating the NC code. The tool orientation is adjusted in such a way that the cutting force is indirectly minimized at the instants of cutting edge points generating the designed surface. The proposed concept is clarified as follows.

Let's consider the ball end milling scenario in Fig. 2a in which CC point is required to be generated. One of the flutes have a large engagement with CWE at the moment when CC is generated with the tool orientation, $\mathbf{z}_{\mathrm{T}}$. In-cut edges of the engaged flute is shown schematically in Fig. $2 \mathrm{~b}$. This large engagement creates cutting forces at the moment of $\mathbf{C C}$ generation which causes the tool and the workpiece to deflect. The result is the large surface geometric error on the designed surface since $\mathbf{C C}$ is dislocated due to tool/workpiece deflection. Now, let's consider an alternative tool axis orientation of the tool, $\mathbf{z}_{\mathrm{T}}^{*}$, as shown in Fig. 2c. In this case, with the identical CWE region as Fig. 2a, the flute engagement is reduced drastically in comparison with the case in Fig. 2a when CC is generated. This engagement is shown schematically as the in-cut edge in Fig. $2 \mathrm{~d}$. The chip thickness hence the cutting forces, deflections and consequently the deflections at contact points CC would be less in the case of Fig. $2 \mathrm{c}$ in comparison with Fig. $2 \mathrm{a}$ due to considerable reduction in the flute engagement. The proposed method in this paper aims at finding alternative tool orientations for all $\mathbf{C L}$ points along the tool pathin such a way that the flutes' cutting edge engagement with the material is minimized, ideally to zero when the designed surface is generated by the contact point CC. 
(a)

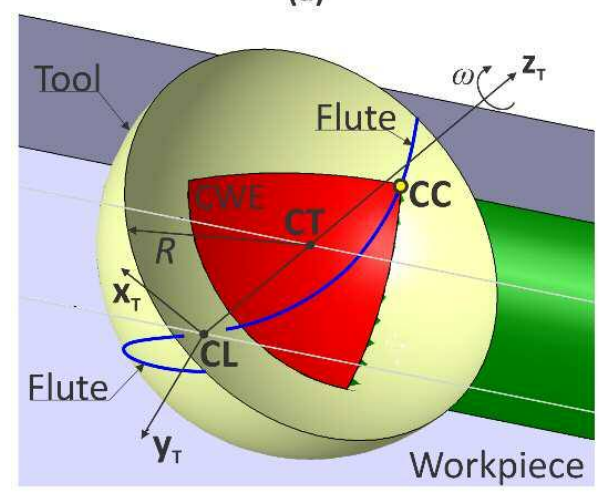

(b)

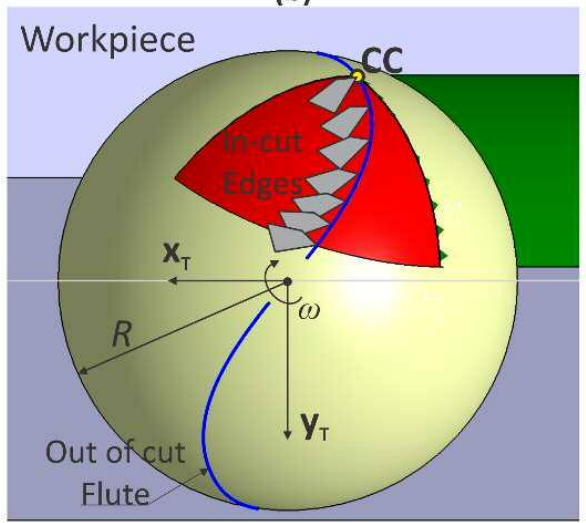

(c)

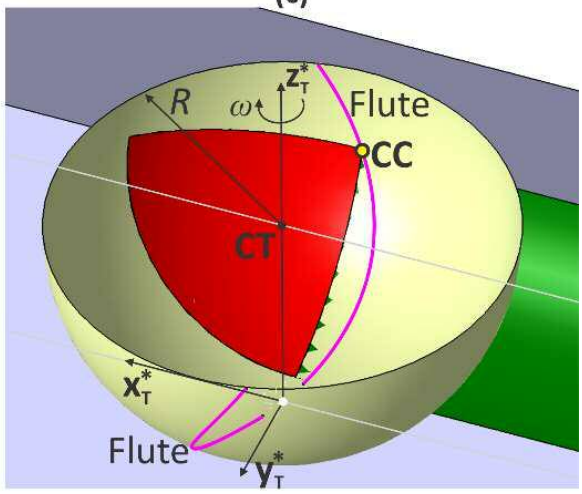

(d)

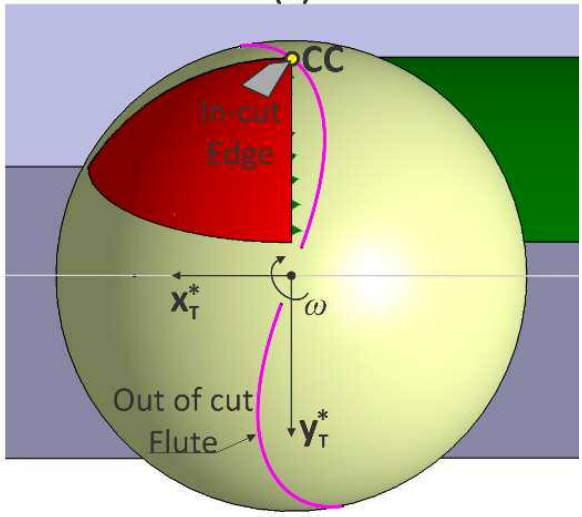

Fig. 2. Core concept of the flute engagement minimization by tool orientation adjustment: a) an example of ball end milling process, $b$ ) the view of $(a)$ along $\mathbf{z}_{\mathrm{T}}$ direction, $c$ ) alternative tool orientation of the case shown in (a), d) the view of (c) along $\mathbf{z}_{T}^{*}$ direction.

\section{Geometry description and coordinate systems construction}

A schematic view of a 5-axis ball end milling process is shown in Fig. $3 a$ in which 5 -axis motions are assigned to the tool. NC codes for such operation includes cutter tip locations, $\mathbf{C L}_{i} \mathbf{S}$, and the orientation of the tool in the workpiece coordinate system, WCS. $i$ is the cutter location counter along the tool path. Three axes of WCS are defined by unit vectors as $\mathbf{x}_{\mathbf{w}}, \mathbf{y}_{\mathbf{w}}$ and $\mathbf{z}_{\mathbf{w}}$ as shown in Fig. 3b. $\mathbf{C T}_{i}$ is the tool center and is defined as $\mathbf{C T}_{i}=\mathbf{C L}_{i}+R \mathbf{z}_{\mathrm{T}}$, where $R$ is the cutter radius and $\mathbf{z}_{\mathbf{T}}$ is a unit vector defining the $z$ axis of the tool coordinate system, TCS. $Y$ axis of TCS, $\mathbf{y}_{\mathbf{T}}$, is defined 

approximated by a connecting vector from $\mathbf{C L}_{i}$ to $\mathbf{C L}_{i+1}$. $\mathbf{X}_{\mathbf{T}}$ is defined using obtained $\mathbf{z}_{\mathbf{T}}$ and $\mathbf{y}_{\mathbf{T}}$ as $\mathbf{x}_{\mathbf{T}}=\left(\mathbf{y}_{\mathbf{T}} \times \mathbf{z}_{\mathbf{T}}\right) /\left|\mathbf{y}_{\mathbf{T}} \times \mathbf{z}_{\mathbf{T}}\right|$.

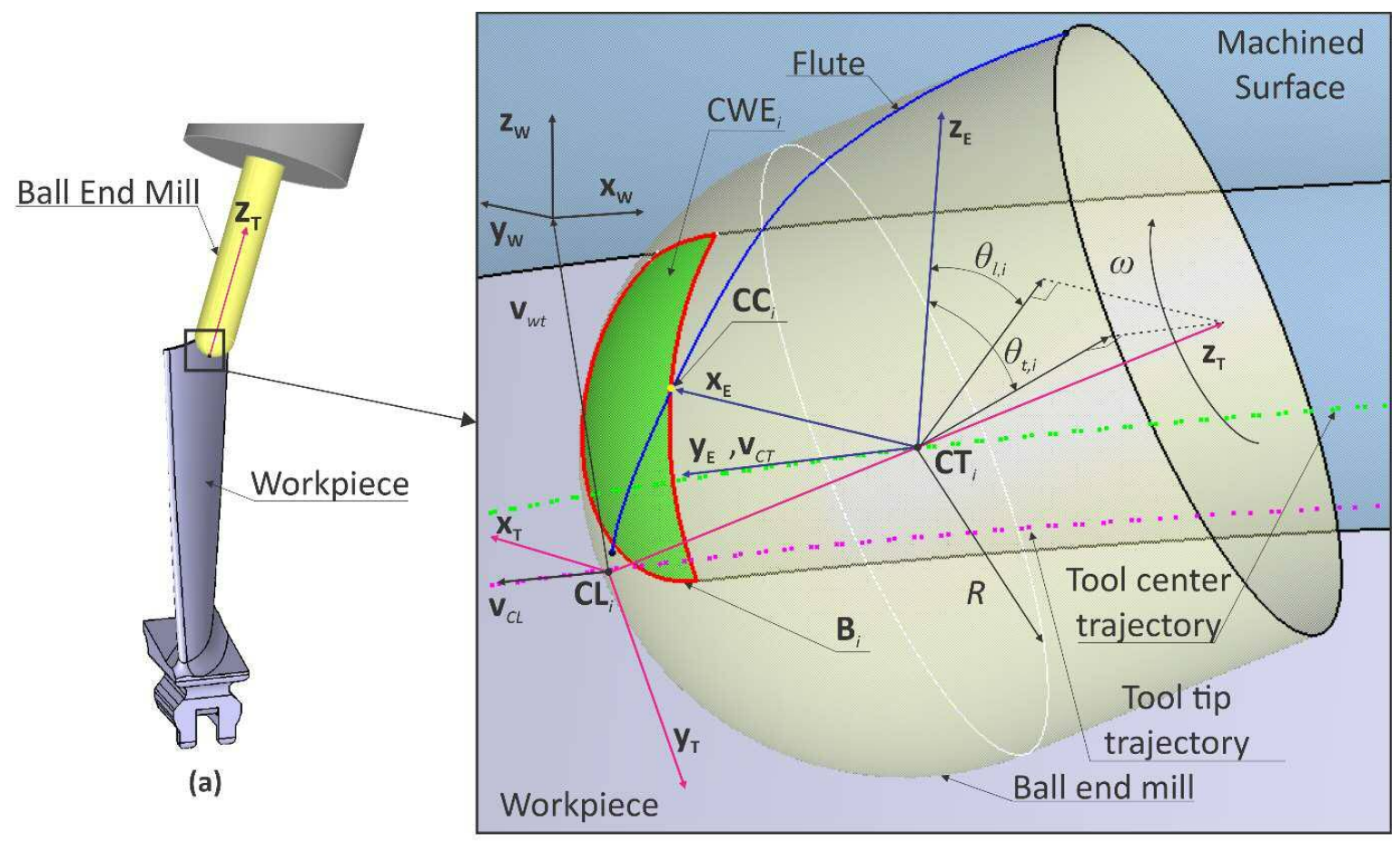

(b)

Fig. 3. Schematic illustration of ball end milling operation: a) ball end mill and the workpiece, b) detailed view of the engagement region between the tool and workpiece.

WCS and TCS are defined based on the data in the NC codes. However, in order to define the engagement coordinate system, ECS, the designed part geometry is required to calculate the cutter contact points, $\mathbf{C C}_{i} s$, along the tool path at $\mathbf{C L}_{i} s . \mathbf{C C}_{i}$ is the contact point where the ball part of the end mill and the designed part are tangent. $\mathbf{C C}_{i}$ is derived by minimizing the distance, $d_{c c, i}$ , between the designed part and tool center, $\mathbf{C T}_{i}$. Therefore, the objective function for calculating $\mathbf{C C}_{i}$ can be written as 


$$
\min \left(d_{c c, i}\right)=\min \left(\left|\mathbf{C T}_{i}-\mathbf{S}\right|\right)
$$

where $\mathbf{S}$ is the designed surface of the designed part. Based on in-cut, no-cut (approaching or retracting) and gouging motions, the value of $\min \left(d_{c c, i}\right)$ can be interpreted as

$$
\left\{\begin{array}{l}
\min \left(d_{c c, i}\right)=R, \quad \text { in-cut } \\
\min \left(d_{c c, i}\right)>R, \quad \text { no-cut } . \\
\min \left(d_{c c, i}\right)<R, \quad \text { gouging }
\end{array}\right.
$$

The minimization problem presented in Eq. (1) when $\min \left(d_{c c, i}\right)=R$ leads to $\mathrm{CC}_{i}=\left[C C_{x}, C C_{y}, C C_{z}\right.$ 1]. $X$ axis of $E C S, \mathbf{X}_{E}$, is defined by a unit vector directed from the $\mathbf{C T}_{i}$ to $\mathbf{C C}_{i} . \mathrm{Y}$ axis of $E C S, \mathbf{Y}_{\mathbf{E}}$, is in the direction of the tool center velocity, $\mathbf{v}_{C T}$. Instead of $\mathbf{v}_{C T}$, a connecting vector from $\mathbf{C T}_{i}$ to $\mathbf{C T}_{i+1}$ can be used. Finally, $\mathbf{z}$ axis of ECS, $\mathbf{z}_{\mathrm{E}}$, can be defined as $\mathbf{z}_{\mathrm{E}}=\left(\mathbf{x}_{\mathrm{E}} \times \mathbf{y}_{\mathrm{E}}\right) /\left|\mathbf{x}_{\mathrm{E}} \times \mathbf{y}_{\mathrm{E}}\right|$.

Cutter workpiece engagement, CWE, which is a contact area between the tool envelope and the in-process model of the workpiece, is obtained using $\mathrm{MACHPRO}^{\circledR}$ software [5] in this paper as shown in Fig. 3b. CWE data in MACHPRO ${ }^{\circledR}$ is defined by strips, along the $z$ axis of the tool, containing entry, $\varphi_{e n}$, and exit, $\varphi_{e x}$, angles. Therefore, $\mathrm{CWE}_{i}$ boundary, $\mathbf{B}_{i}$, can be represented by points corresponding to $\varphi_{e n}$ s and $\varphi_{e x}$ s in TCS as

$$
P_{C W E, e n}=\left[\begin{array}{c}
\sqrt{z(2 R-z)} \sin \left(\varphi_{e n}\right) \\
\sqrt{z(2 R-z)} \cos \left(\varphi_{e n}\right) \\
z \\
1
\end{array}\right], P_{C W E, e x}=\left[\begin{array}{c}
\sqrt{z(2 R-z)} \sin \left(\varphi_{e x}\right) \\
\sqrt{z(2 R-z)} \cos \left(\varphi_{e x}\right) \\
z \\
1
\end{array}\right]
$$


where $P_{C W E, e n}$ and $P_{C W E, e x}$ are points on entry and exit boundaries of $\mathbf{B}_{i}, \mathbf{B}_{i}=P_{C W E, e n} \cup P_{C W E, e x}$, respectively. $\mathbf{C C}_{i}$ is the only point on $\mathbf{B}_{i}$, which generates the final surface and all other points of CWE boundary are removed during machining.

In the proposed tool orientation adjustment, tool center, $\mathbf{C T}_{i}$, is kept unchanged and the tool is rotated around this point. In addition, since only the ball part is involved in cutting in finishing operations, CWE always lies on spherical part of the ball end mill. In this way, changing the orientation of the tool does not change $\mathrm{ECS}, \mathrm{CC}_{i}$ and $\mathrm{CWE}$ of the nominal tool path before tool orientation adjustment. This concept is illustrated in Fig. 4. However, TCS changes by changing the tool orientation. Therefore, $\mathrm{CC}_{i}$ and $\mathrm{CWE}$, which are calculated in TCS, are transformed to ECS before adjusting the tool orientation. In order to do so, $\mathbf{C C}_{i}$ and $\mathbf{B}_{i}$ are transformed as

$$
\begin{gathered}
\mathrm{CC}_{i, \mathrm{E}}=\mathrm{M}_{\mathrm{T}-\mathrm{E}} \mathrm{CC}_{i}, \\
\mathbf{B}_{i, \mathrm{E}}=\mathrm{M}_{\mathrm{T}-\mathrm{E}} \mathbf{B}_{i},
\end{gathered}
$$

where $\mathbf{M}_{\mathbf{T}-\mathrm{E}}$ is the homogeneous transformation matrix from TCS to ECS and can be written as

$$
\mathbf{M}_{T-E}=\left[\begin{array}{cccc}
\mathbf{x}_{\mathrm{E}} \cdot \mathbf{x}_{\mathrm{T}} & \mathbf{x}_{\mathrm{E}} \cdot \mathbf{y}_{\mathrm{T}} & \mathbf{x}_{\mathrm{E}} \cdot \mathbf{z}_{\mathrm{T}} & 0 \\
\mathbf{y}_{\mathrm{E}} \cdot \mathbf{x}_{\mathrm{T}} & \mathbf{y}_{\mathrm{E}} \cdot \mathbf{y}_{\mathrm{T}} & \mathbf{y}_{\mathrm{E}} \cdot \mathbf{z}_{\mathrm{T}} & 0 \\
\mathbf{z}_{\mathrm{E}} \cdot \mathbf{x}_{\mathrm{T}} & \mathbf{z}_{\mathrm{E}} \cdot \mathbf{y}_{\mathrm{T}} & \mathbf{z}_{\mathrm{E}} \cdot \mathbf{z}_{\mathrm{T}} & 0 \\
0 & 0 & 0 & 1
\end{array}\right] .
$$




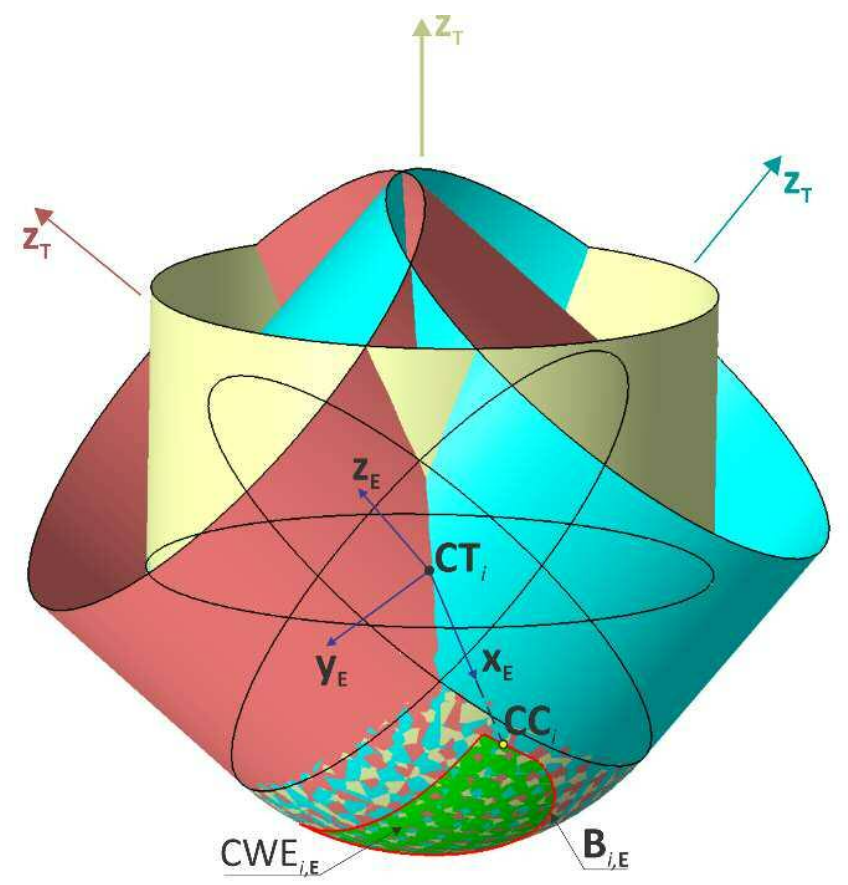

Fig. 4. Three tool orientations with the common $\mathbf{C T}_{i} \cdot \mathbf{C} \mathbf{T}_{i}, \mathbf{C W E}$ and $\mathbf{C C}_{i}$ remain unchanged for all three tool orientations.

To further emphasise on the concept presented in Fig. 4, it should be noted that the idea of the present paper does not lead to reduction in the cutter workpiece engagement (CWE). As shown in Fig. 4, the tool orientation change around the tool center does not change CWE. Therefore, the material removal rate (MRR) does not change either. However, what is changed is the tool's flutes' cutting edge engagement at the moment when CC point is generated on the designed surface. The presented idea in the paper aims at minimizing this cutting edge engagement, ideally to zero. Ideally, zero engagement leads to zero cutting forces and zero surface error at $\mathbf{C C}$ when CC is generated on the designed surface.

Tilt, $\theta_{t, i}$, and lead, $\theta_{l, i}$, angles are defined in ECS using the $z$ axis of $\mathrm{TCS}$ at $\mathbf{C L}_{i}$. The angle between the projection of $\mathbf{z}_{\mathbf{T}}$ on $\mathbf{z}_{\mathrm{E}} \mathbf{y}_{\mathbf{E}}$ plane and $\mathbf{z}_{\mathbf{E}}$ is tilt angle, $\theta_{t, i}$, and the angle between the projection of 
$\mathbf{Z}_{\mathbf{T}}$ on $\mathbf{Z}_{\mathrm{E}} \mathbf{X}_{\mathrm{E}}$ plane and $\mathbf{z}_{\mathrm{E}}$ defines the lead angle, $\theta_{l, i}$. Therefore, the equations of $\theta_{t, i}$ and $\theta_{l, i}$ are derived as

$$
\begin{gathered}
\theta_{t, i}=\tan ^{-1}\left(\frac{a_{x}}{a_{z}}\right), \theta_{l, i}=\tan ^{-1}\left(\frac{a_{y}}{a_{z}}\right), \\
{\left[\begin{array}{llll}
a_{x} & a_{y} & a_{z} & 1
\end{array}\right]^{T}=\mathbf{M}_{\mathbf{W}-\mathrm{E}}\left[\begin{array}{c}
\mathbf{z}_{\mathbf{T}} \\
1
\end{array}\right],}
\end{gathered}
$$

where $\mathbf{M}_{\mathrm{W}-\mathrm{E}}$ is the homogeneous transformation matrix from WCS to ECS and is written as

$$
\mathbf{M}_{W-E}=\left[\begin{array}{cccc}
\mathbf{x}_{E} \cdot \mathbf{x}_{W} & \mathbf{x}_{E} \cdot \mathbf{y}_{W} & \mathbf{x}_{E} \cdot \mathbf{z}_{W} & 0 \\
\mathbf{y}_{E} \cdot \mathbf{x}_{W} & \mathbf{y}_{E} \cdot \mathbf{y}_{W} & \mathbf{y}_{E} \cdot \mathbf{z}_{W} & 0 \\
\mathbf{z}_{E} \cdot \mathbf{x}_{W} & \mathbf{z}_{E} \cdot \mathbf{y}_{W} & \mathbf{z}_{E} \cdot \mathbf{z}_{W} & 0 \\
0 & 0 & 0 & 1
\end{array}\right]
$$

Since $\theta_{t, i}$ and $\theta_{l, i}$ are derived using the given tool path, given $\mathbf{z}_{\mathbf{T}}$ in Eq. (8), Eq. (7) is the forward equation of the tilt and lead angles.

The equation of the cutting edge of the flute on the ball portion of the ball end mill [22] in TCS can be written as

$$
\mathbf{r}_{m}=\left[\begin{array}{c}
\sqrt{z(2 R-z)} \cos \left(-\frac{\sqrt{z(2 R-z)} \tan \left(\alpha_{e}\right)}{R^{2}}+\varphi_{0}+\sum_{m=1}^{M} \varphi_{p, m}\right) \\
-\sqrt{z(2 R-z)} \sin \left(-\frac{\sqrt{z(2 R-z)} \tan \left(\alpha_{e}\right)}{R^{2}}+\varphi_{0}+\sum_{m=1}^{M} \varphi_{p, m}\right) \\
z \\
1
\end{array}\right],
$$


where $m, M, \alpha_{e}, \varphi_{p, m}$ and $\varphi_{0}$ are flute number, number of flutes, helix angle at the connection of the ball and cylindrical segment of the tool, flute pitch angle and immersion angle, respectively. The immersion angle in which a flute is passing through $\mathbf{C C}_{i}$ can be calculated using Eq. (10) as

$$
\varphi_{0, c c}=\frac{C C_{z} \sqrt{C C_{z}\left(2 R-C C_{z}\right)}}{R^{2}} \tan \left(h_{e}\right)+\cos ^{-1}\left(\frac{C C_{x}}{\sqrt{C C_{z}\left(2 R-C C_{z}\right)}}\right)
$$

where $C C_{x}, C C_{y}$ and $C C_{z}$ are the $\mathrm{x}, \mathrm{y}$ and $\mathrm{z}$ coordinates of $\mathrm{CC}_{i, \mathrm{~T}}$, respectively.

\section{Optimization for Tool Axis Adjustment}

The proposed optimization problem searches for optimal tilt, $\theta_{t, i}^{*}$, and lead, $\theta_{l, i}^{*}$, angles at $\mathbf{C T}_{i}$ in such a way that the trapped length of the flutes inside $\mathrm{CWE}_{i}$ is minimized when $\mathrm{CC}_{i}$ is generated on the designed surface, $\mathbf{S}$. The geometrical representation of $\mathbf{C C}_{i}$ generation is expressed when a flute passes through $\mathbf{C C}_{i}$. The optimization search considers the designed variables, $\Gamma_{i}^{d}=\left\{\theta_{t, i}^{d}, \theta_{l, i}^{d}\right\}$, as inputs to calculate the flute's cutting edge engagement with CWE. Therefore, the inverse equation of $\theta_{t, i}^{d}$ and $\theta_{l, i}^{d}$ can be derived using Eqs. (7) and (8) as

$$
\left[\begin{array}{c}
\mathbf{z}_{\mathbf{T}} \\
1
\end{array}\right]=\left(\mathbf{M}_{\mathbf{W}-\mathbf{E}}\right)^{-1}\left[\tan \left(\theta_{t, i}^{d}\right) \tan \left(\theta_{l, i}^{d}\right) \quad 1 \quad 1\right]^{T}
$$

Therefore, $\mathbf{z}$ axis of TCS, $\mathbf{z}_{\mathbf{T}}$, is calculated for given values of design variables, $\theta_{t, i}^{d}$ and $\theta_{l, i}^{d}$. Other two axes of TCS, $\mathbf{z}_{\mathbf{y}}$ and $\mathbf{z}_{\mathbf{x}}$, are defined as discussed in Section 3 (WCS, ECS, $\mathbf{B}_{i, \mathrm{E}}, \mathbf{C C}_{i, \mathrm{E}}$ and $\mathbf{C T}_{i, \mathbf{W}}$ remain unchanged during the optimization search process). Since TCS is fully defined, boundary of CWE and $\mathrm{CC}_{i, \mathrm{E}}$ can be transformed back to TCS from ECS as 


$$
\mathbf{B}_{i, \mathbf{T}}=\left(\mathbf{M}_{\mathbf{T}-\mathbf{E}}\right)^{-1} \mathbf{B}_{i, \mathbf{E}}, \mathbf{C C}_{i, \mathbf{T}}=\left(\mathbf{M}_{\mathbf{T}-\mathbf{E}}\right)^{-1} \mathbf{C C}_{i, \mathrm{E}},
$$

respectively.

\subsection{Objective function}

The engagement length of the flutes' cutting edges with CWE is the objective function of the proposed tool adjustment method. In order to calculate this engagement length for a given $\Gamma_{i}^{d}$, it is more convenient to project the flutes' cutting edges and CWE to $\mathbf{x}_{\mathbf{T}} \mathbf{T}$ T plane as shown in Fig. 5. Since the CWE is always on the spherical part of the tool, the projection of the flutes' cutting edges and CWE do not have any self intersection. The equation of the projected boundary of CWE, $\mathbf{B}_{i, T}^{p}$, can be formulated using Eq. (13) as

$$
\mathbf{B}_{i, T}^{P}=\left[\begin{array}{llll}
1 & 0 & 0 & 0 \\
0 & 1 & 0 & 0 \\
0 & 0 & 0 & 0 \\
0 & 0 & 0 & 1
\end{array}\right] \mathbf{B}_{i, T} .
$$

For given values of $\Gamma_{i}^{d}$, the immersion angle of the flutes, $\varphi_{0, c c}^{d}$, when one of the flute's cutting edge passes through $\mathbf{C C}_{i}$, where $\mathbf{C C}_{i}$ is calculated by Eq. (13), is derived by Eq. (11). Therefore, the flutes' equations are obtained by Eq. (10). Although more than one flute can be engaged with $\mathrm{CWE}, \mathrm{CC}_{i}$ is generated by one flute only. The equation of the flute $(m=1)$ passing through $\mathrm{CC}_{i}$ can be written as 


$$
r_{1}=\left[\begin{array}{c}
\sqrt{z(2 R-z)} \cos \left(-\frac{\sqrt{z(2 R-z)} \tan \left(\alpha_{e}\right)}{R^{2}}+\varphi_{0, c c}^{d}\right) \\
-\sqrt{z(2 R-z)} \sin \left(-\frac{\sqrt{z(2 R-z)} \tan \left(\alpha_{e}\right)}{R^{2}}+\varphi_{0, c c}^{d}\right) \\
z \\
1
\end{array}\right] .
$$

The equation of $\mathbf{r}_{1}$ projection on $\mathbf{X}_{\mathbf{T}} \mathbf{Y}$ T plane, $\mathbf{r}_{1}^{p}$, can be written as

$$
\mathbf{r}_{1}^{p}=\left[\begin{array}{llll}
1 & 0 & 0 & 0 \\
0 & 1 & 0 & 0 \\
0 & 0 & 0 & 0 \\
0 & 0 & 0 & 1
\end{array}\right] \mathbf{r}_{1}
$$

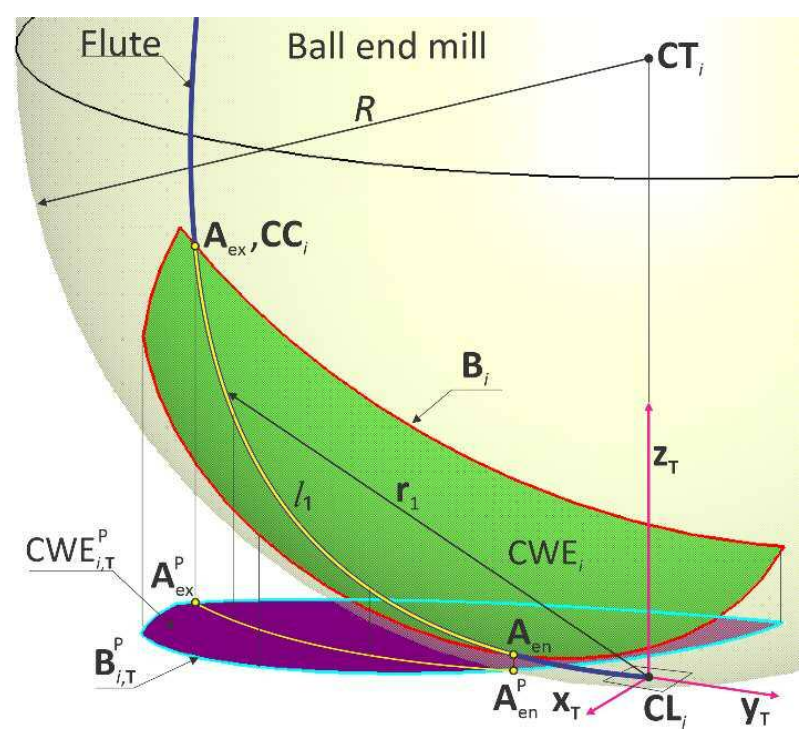

Fig. 5. Illustration of the engagement length, $l_{1}$, of a flute's cutting edge with CWE.

$\mathbf{r}_{1}$ has two intersection points with $\mathbf{B}_{i, \mathrm{~T}}$ as $\mathbf{A}_{\mathrm{en}}$ and $\mathbf{A}_{\mathrm{ex}}$ as shown in Fig. 5 . The trapped length of $\mathbf{r}_{1}$ in $\mathbf{B}_{i, \mathbf{T}}, l_{1}$, can be formulated as 


$$
l_{1}=\int_{A_{e n, z}}^{A_{e x, z}}\left(\frac{\sqrt{\left(R^{6}-18 R^{3} z^{3}+33 R^{2} z^{4}-20 R z^{5}+4 z^{6}\right) \cos \left(\alpha_{e}\right)^{2}+18 z^{3}\left(R-\frac{z}{2}\right)\left(R-\frac{2 z}{3}\right)^{2}}}{\cos \left(\alpha_{e}\right) R^{2} \sqrt{z(2 R-z)}}\right) d z
$$

where $A_{e n, z}$ and $A_{e x, z}$ are the corresponding z coordinates of $\mathbf{A}_{\mathrm{en}}$ and $\mathbf{A}_{\mathrm{ex}}$, respectively. In order to find $\mathbf{A}_{\mathrm{en}}$ and $\mathbf{A}_{\mathrm{ex}}$, it is more convenient to work with the projected the flute's cutting edge and CWE, $\mathbf{r}_{1}^{\mathrm{p}}$ and $\mathbf{B}_{i, T}^{\mathrm{p}}$, than $\mathbf{r}_{1}$ and $\mathbf{B}_{i, T}$ themselves. $\mathbf{B}_{i, T}^{\mathrm{p}}$ and $\mathbf{r}_{1}^{\mathrm{p}}$ are discretized into line segments and then intersected by polyxpoly function in MATLAB to obtain $\mathbf{A}_{e n}^{\mathrm{p}}$ and $\mathbf{A}_{e x}^{\mathrm{p}}$ as shown in Fig. 5. $A_{e n, z}$ and $A_{e x, z}$ can be found using Eq. 12 and obtained $A_{e n}^{p}$ and $A_{e x}^{p}$ as

$$
\begin{aligned}
& A_{e n, z}=R-\sqrt{R^{2}-\left(\left(A_{e n, x}^{\mathrm{p}}\right)^{2}+\left(A_{e n, y}^{\mathrm{p}}\right)^{2}\right)}, \\
& A_{e x, z}=R-\sqrt{R^{2}-\left(\left(A_{e x, x}^{\mathrm{p}}\right)^{2}+\left(A_{e x, y}^{\mathrm{p}}\right)^{2}\right)},
\end{aligned}
$$

respectively, where $\quad \mathbf{A}_{e n}^{\mathrm{p}}=\left[A_{e n, x}^{\mathrm{p}}, A_{e n, y}^{\mathrm{p}}, 0\right], \quad \mathbf{A}_{e x}^{\mathrm{p}}=\left[A_{e x, x}^{\mathrm{p}}, A_{e x, y}^{\mathrm{p}}, 0\right], \quad \mathbf{A}_{e n}=\left[A_{e n, x}, A_{e n, y}, A_{e n, z}\right] \quad$ and $\mathbf{A}_{e x}=\left[A_{e x, x}, A_{e x, y}, A_{e x, z}\right]$. Therefore, the lower and upper limits of the integration in Eq. (17) , $A_{e n, z}$ and $A_{e x, z}$, are obtained using Eqs. (18) and (19). Eq. (17) is the trapped length of the flute's cutting edge passing through the $\mathbf{C C}_{i}$, however, more than one flute could be engaged with $\mathrm{CWE}$. Therefore, the general equation of Eq. (17) can be written as

$$
L_{i}=\sum_{m=1}^{M} l_{m}
$$

to consider all flutes, where $L$ is the total engagement length of all flutes in CWE. 
If CWE boundary, $\mathbf{B}_{i, T}$, is a convex hull, not a concave hull, a simplified representation of the total engagement length could be used. Instead of using Eq. (17) to calculate $l_{m}$, the distance between points $\mathbf{A}_{e n}$ and $\mathbf{A}_{e x}$ could be used. Therefore, Eq. (20) can be re-written as

$$
L_{i} \equiv \sum_{m=1}^{M}\left|\mathbf{A}_{e n} \mathbf{A}_{e x}\right|_{m}
$$

where $\left|\mathbf{A}_{e n} \mathbf{A}_{e x}\right|_{m}$ is the distance between $\mathbf{A}_{e n}$ and $\mathbf{A}_{e x}$ for flute number $m$ in engagement with CWE. $\mathbf{B}_{i, \mathrm{~T}}$ is a concave hull if the workpiece has unsmooth surfaces. In this case, even number of intersection points, $2 K$, between $\mathbf{r}_{m}$ and $\mathbf{B}_{i, \mathrm{~T}}$ could be found. Therefore, Eq. (21) could be reformulated as

$$
L_{i} \equiv \sum_{m=1}^{M} \sum_{k=1}^{K}\left|\mathbf{A}_{e n, k} \mathbf{A}_{e x, k}\right|_{m}
$$

It should be noted that Eqs. (20)-(22)are formulated for the general topological situation between CWE and the flutes. However, in most finishing operations, CWE would be relatively small and only one flute is in engagement with $\mathrm{CWE}$ when $\mathrm{CC}_{i}$ is generated. This situation is most likely dominant especially if a tool with low number of flutes, large pitch angle, is used. In this case, the flute summation operator could be dropped in Eqs. (20)-(22). In addition, after semi-finishing processes, the workpiece surface would be smooth enough to avoid concave CWEs. Therefore, in this case, the summation operator for intersection points could be dropped too. If both summations in Eq. (22) can be dropped, Eq. (17) or simply $\left|\mathbf{A}_{e n} \mathbf{A}_{e x}\right|$ can be used directly as the flute's cutting edge engagement length, $L_{i}$. 
Finally, the objective function of the optimization problem, $F_{o p}$, can be written as

$$
F_{o p, i}=L_{i}
$$

in which the tool orientation is adjusted in such way that optimized solutions, optimal lead and tilt angles, result in minimum engagement length, $L_{i}$. The solutions of the optimization problem, $\Gamma_{i}^{*}=\left\{\theta_{t, i}^{*}, \theta_{l, i}^{*}\right\}$, are substituted to Eq. 9 to derive the optimal tool orientation, tool axis $\mathbf{z}_{\mathrm{T}, i, \mathbf{E}}^{*}$ at $\mathbf{C L}_{i}$. Based on the optimal tool axis, $\mathbf{z}_{\mathrm{T}, i, \mathrm{E}}^{*}$, and tool center point, the tool tip, cutter location, is obtained as

$$
\mathrm{CL}_{i, \mathbf{W}}^{*}=\mathbf{C T}_{i, \mathbf{W}}-R \mathbf{z}_{\mathbf{T}, i, \mathbf{W}}^{*}
$$

where

$$
\left[\begin{array}{c}
\mathbf{z}_{\mathbf{T}, i, \mathbf{W}}^{*} \\
1
\end{array}\right]=\left(\mathbf{M}_{\mathbf{W}-\mathbf{E}}\right)^{-1}\left[\begin{array}{c}
\mathbf{z}_{\mathbf{T}, i, \mathbf{E}}^{*} \\
1
\end{array}\right] .
$$

$\mathbf{z}_{\mathrm{T}, i, \mathrm{~W}}^{*}$ and $\mathbf{C L}_{i, \mathrm{~W}}^{*}$ are the new tool orientation and cutter location, respectively, for the adjusted tool path while $\mathbf{C T}_{i, \mathrm{~W}}$ does not change along the nominal tool path, $\mathbf{z}_{\mathrm{T}, i, \mathrm{~W}}$ and $\mathbf{C L}_{i, \mathrm{~W}}$.

\subsection{Constraints}

In finishing processes using ball end mills, it is required to avoid the engagement of the cylindrical part of the tool with the workpiece. In the optimization process, some values of design variables could lead to an orientation in which CWE does not lie on the ball part of the tool. Therefore, to avoid this condition, the first constraint is formulated using Eq. (13) as 


$$
\max \left(\left(\mathbf{B}_{i, \mathbf{T}}\right)_{z}\right) \leq R
$$

where $\left(\mathbf{B}_{i, \mathbf{T}}\right)_{z}$ is the $\mathbf{z}$ coordinates of $\mathbf{B}_{i, \mathbf{T}}$ in the TCS.

In ball end milling processes, it is desired to avoid the engagement of the tool tip with the workpiece due to zero cutting velocity at this location which results in bad surface finish. This constraint can be formulated as

$$
\mathrm{CL}_{i} \notin \mathrm{CWE}_{i} \text {. }
$$

Eq. (27) implies that the tool tip must stay outside of $\mathrm{CWE}_{i}$. It is less computationally expensive to implement this condition for the projection of $\mathrm{CWE}_{i}$ to $\mathbf{X}_{\mathbf{T}} \mathbf{Y}_{\mathbf{T}}$ plane using Eq. (13). Therefore, the problem is reduced to Point in Polygon Problem, PIP, which can be implemented by inpolygon function in MATLAB in which the point is $\mathbf{C L}_{i}$ and the polygon is $\mathbf{B}_{i, \mathrm{~T}}^{p}$.

The last constraint is based on preventing the collision between the tool shank with the workpiece for given values of design variables, $\Gamma_{i}^{d}=\left\{\theta_{t, i}^{d}, \theta_{l, i}^{d}\right\}$. This constraint is formulated as

$$
\mathbf{H}_{T, i} \cap \mathbf{H}_{W, i} \in \varnothing,
$$

where $\mathbf{H}_{T, i}$ and $\mathbf{H}_{W, i}$ are the convex hulls of the tool shank-tool holder and workpiece, respectively, at $\mathbf{C L}_{i}$. The constraint in Eq. (28) is implemented as upper and lower limits of $\Gamma_{i}^{d}=\left\{\theta_{t, i}^{d}, \theta_{l, i}^{d}\right\}$ along the tool path by getting the intersection of Standard Triangle Language (STL) formats of the workpiece and tool at $\mathbf{C L}_{i}$. 


\subsection{Initial values of the optimization problem}

Initial values of the design variables are selected at $\mathbf{C L}_{i}$ in such a way that the solutions have small deviation from the solutions at $\mathbf{C L}_{i-1}$. In other words, initial values are selected in such a way that adjusted tool orientation have small and smooth variation along the tool path. For this purpose, one method is to select proper initial values for the optimization problem to start with. The initial

values of the design variables at $\mathbf{C L}_{i}, \Gamma_{i}^{d}=\left\{\theta_{t, i}^{d}, \theta_{l, i}^{d}\right\}$, are selected as the solutions at $\mathbf{C L}_{i-1}$, $\Gamma_{i-1}^{*}=\left\{\theta_{t, i-1}^{*}, \theta_{l, i-1}^{*}\right\}$. Moreover, this method reduces the computational time of the optimisation problem as well because $\Gamma_{i-1}^{*}$ and $\Gamma_{i}^{*}$ are very close to each other in reality especially in finishing of sculptured surfaces when the $\mathrm{NC}$ code includes very dense and close $\mathrm{CL}_{i}$ s where $\mathrm{CWE}_{i}$ and $\mathrm{CWE}_{i-1}$ would not have a drastic geometric deviation.

\subsection{Discussion on the minimized engagement}

In finishing operations using a ball end mill, $\mathrm{CWE}_{i}$ is small in comparison with the semi-spherical portion of the ball end mill and $\mathrm{CC}_{i}$ is located close to a corner of $\mathrm{CWE}_{i}$ due to small scallop height, as shown in Fig. $6 a$. In this case, $l_{1}^{*}$ would be very small and most of the flute's cutting edge lies outside of $\mathrm{CWE}_{i}$ as in Fig. 6a. In the general case of ball end milling where $\mathrm{CWE}_{i}$ and consequently scallop height are large and $\mathrm{CC}_{i}$ would be far from the corners of $\mathrm{CWE}_{i}$. In this case, the minimization problem might not be able to reduce $l_{1}$ significantly as shown in Fig. $6 \mathrm{~b}$. This limitation originates in the flute geometry.

For the same $\mathrm{CWE}_{i}$ and $\mathrm{CC}_{i}$ in Fig. 5b, Fig. $6 \mathrm{c}$ shows an alternative tool orientation in which a left hand flute could have no engagement with $\mathrm{CWE}_{i}$ when $\mathrm{CC}_{i}$ is generated. Therefore, the 
optimization problem would lead to a solution where $l_{1}^{*}=0$. This situation happens when $\mathbf{C C}_{i}$ is located exactly at the corner to $\mathrm{CWE}_{i}$ or a proper flute hand (left or right) is used. Using a proper flute leads to a situation in which the flute could be tangent to $\mathrm{CWE}_{i}$ at $\mathrm{CC}_{i}$ as shown in Fig. $6 \mathrm{c}$.

Down milling machining are desired for finishing operations due to the outward deflection of the tool and under-cut of the workpiece. The machining operations in Figs. 6a-c are down milling. However, in up-milling machining, if a right hand tool was chosen even with a large $\mathrm{CWE}_{i}$, the flute's cutting edge would be tangent to $\mathrm{CWE}_{i}$ at $\mathrm{CC}_{i}$ and consequently it leads to $l_{1}^{*}=0$ as shown in Fig. 6d.

In general and qualitatively speaking, if the tool radius is small, CWE area is large and/or the number of flutes is large (due to small pitch angle), more than one flute might engage with CWE when CC point is generated. In finishing operations, since the CWE is very small, one flute is engaged with CWE most probably.

However, it is possible to draw a rule of thumb relationship considering entry and exit angles of CWE to examine when the one flute engagement situation happens. This rule of thumb could be expressed as: assuming the tool tip is out of CWE (out of cut), if the largest difference between CWE entry and exit angles along the tool's $z$ axis is less than the tool's flute pitch angle, one flute engagement most probably occurs. However, the reader is referred to the mathematical model represented in the paper for accurate calculation of the number of flutes engaged with CWE. If more than one flute is in engagement, the presented work could still be effective in reducing the surface error by changing the tool orientation. 
(a)

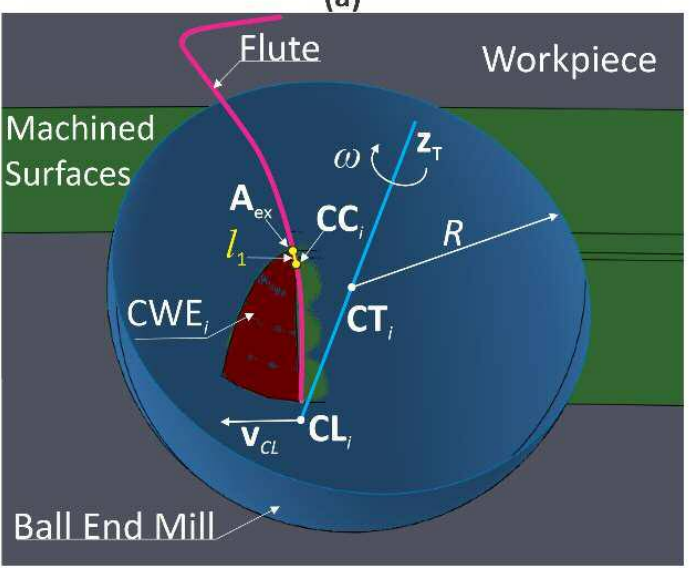

(c)

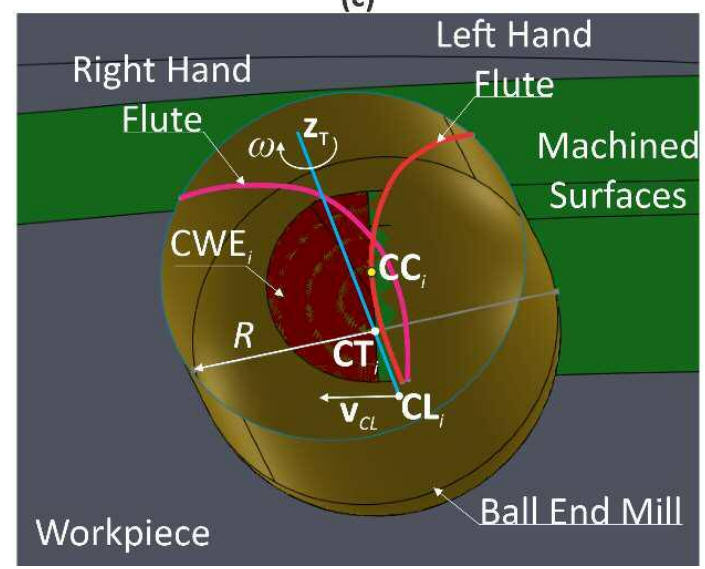

(b)

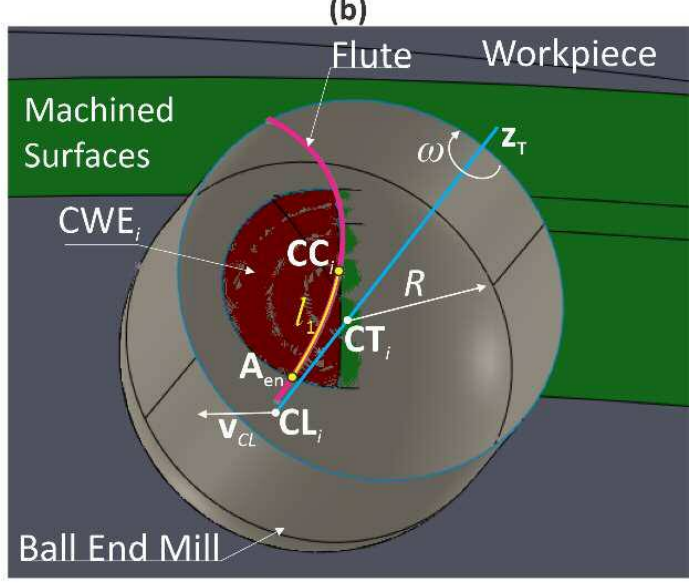

(d)

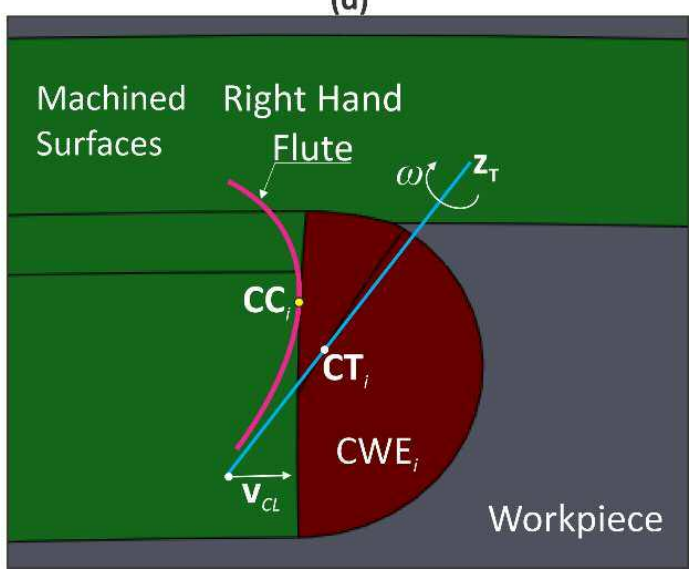

Fig. 6. General topology between $\mathrm{CWE}_{i}$ and the flute's cutting edge, a) Down milling, right hand spiral flute, most of the flute is outside of $\mathrm{CWE}_{i}$ when passing through $\left.\mathrm{CC}_{i}\right)$, b) Down milling, large $\mathrm{CWE}_{i}$ due to large depth of cut. A part of flute is always trapped in the $\mathrm{CWE}_{i}$. c) Down milling, a left hand flute, even with large depth of cut, the flute can make the tangency constraint between the flute and $\mathbf{C C}_{i}$ while whole flute is outside of $\mathrm{CWE}_{i}$, d) Up milling, a right hand flute, the flute can make the tangency constraint between the flute and $\mathrm{CC}_{i}$ while whole flute is outside of $\mathrm{CWE}_{i}$.

Looking at Fig. 6, one could conclude that cutting forces are proportional to the flute engagement. It is not possible to draw a general conclusion of proportionality, especially for ball end mills. In ball end mills, the lower (along $z$ axis of the tool from tool tip) portions of the tool create more force than the higher portions due to lower cutting velocity at the lower levels. In addition, cutting force coefficients vary along $z$ axis for a ball end mill tool. However, if the 
engagement is drastically reduced (as conducted in the presented method), especially at the lower levels, the cutting force would reduce too. This is the case shown in Fig. 6a which is common for finishing processes.

\section{Experimental validation}

In order to validate the tool orientation adjustment method, a down milling five-axis machining test is conducted on QUASER UX600 five-axis CNC Machining Center. The cutting tool is Sandvik R216.44-12030-AK22A H10F 2-fluted cemented carbide ball end mill with $12 \mathrm{~mm}$ diameter, 30 deg nominal helix angle, 15 deg nominal rake angle and the workpiece is a Al7050-T7451 block. Fig. 7a shows the experimental setup: The cutting tool, with $62.2 \mathrm{~mm}$ stickout of a colleted ER32 chuck, has weak static stiffness at the tool tip $(5.6 \mathrm{~N} /$ micrometer as averaged value in two orthogonal radial directions) which is preferred during the tests, and the workpiece is a rigid block mounted on a vise fixture. Feed rate and spindle speed are $600 \mathrm{~mm} / \mathrm{min}$ and $750 \mathrm{rev} / \mathrm{min}$, respectively, under chatter-free conditions. The stable cutting conditions for the nominal cutting tool path were designed by modal analysis and further computation of stability in accordance with Refs. [23] and [16]. The spindle speed is set at a low value to benefit of the increased machining stability in the process damping zone. Considering the relatively small dynamic cutting forces in finishing operations, the stable machining is presumed to be not influenced by optimization of the tool path. The machined surface after both nominal and optimized cuts are checked to validate the chatter-free cutting.

CATIA V $5^{\circledR}$ is used for workpiece modeling, tool path creation and G-Code generation. The tool path has two parts, a straight cut (axial and radial depths of cut are $5.2 \mathrm{~mm}$ and $3 \mathrm{~mm}$, 
respectively) followed by a 3D free form path (the axial depth of cut varies from $5.2 \mathrm{~mm}$ to 3.5 $\mathrm{mm}$ and then to $5.5 \mathrm{~mm}$ and the radial depth of cut varies from $3 \mathrm{~mm}$ to $2 \mathrm{~mm}$ and then to 4.5 $\mathrm{mm}$ along the free form path). The machined workpiece and the tool path are shown in Fig. 7a. The optimization problem is implemented in $\mathrm{MATLAB}^{\circledR}$ using fmincon function with interiorpoint algorithm. The objective functions and constraints are given as implicit functions by series of .m files to the fmincon function.

The workpiece and $\mathrm{CWE}_{i}$ at three cutter locations, $i=127, i=359$ and $i=498$ as examples, along the tool path are shown in Fig. 7a. $\mathbf{r}_{1}$ and $l_{1}$ represent the flute's cutting edge and its engagement with $\mathrm{CWE}_{i}$ for nominal cutter locations and tool orientations. $\mathrm{r}_{1}^{*}$ is the optimal flute's cutting edge calculated in the tool coordinated system resulted from tool orientation adjustment, TCS ${ }^{*}$. As shown in Fig. $7 a, \mathbf{r}_{1}^{*} \mathbf{s}$ do not have any engagement when $\mathbf{C C}_{i s}$ are created. Therefore, the geometric surface errors would be zero theoretically at the $\mathbf{C C}_{i s}$ 's trajectory, $\mathbf{C C}$. TCSs are adjusted to TCS*, however, ECSs are kept unchanged during the optimization problem. Therefore, tool center's trajectory, $\mathbf{C T}$, remains the same for both nominal and optimal tool paths. 

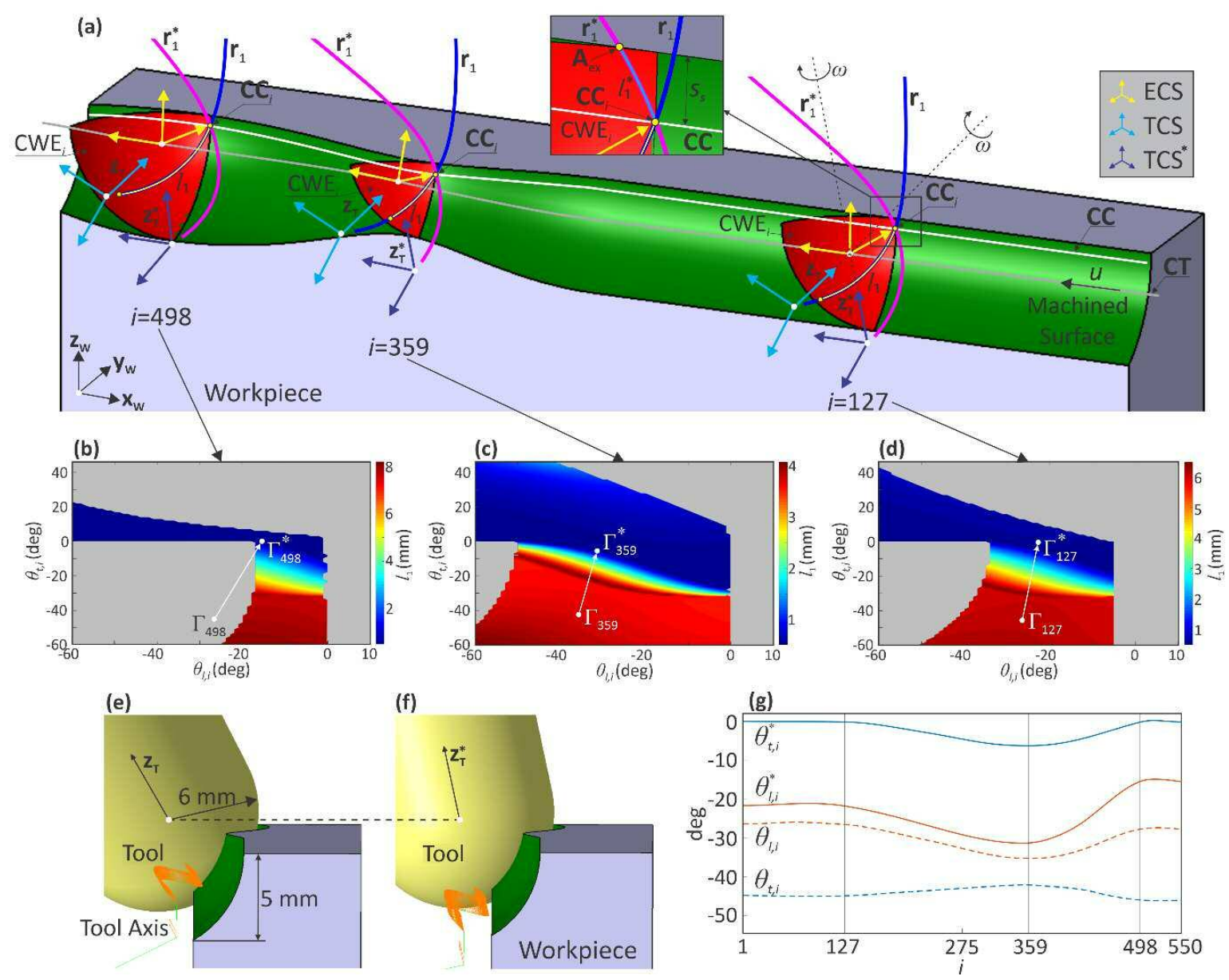

Fig. 7. Illustration of the experimental test, a) three CWEs and corresponding detailed geometries are shown along the tool machined surface, $\mathrm{b}-\mathrm{d}$ ) $l_{1}$ vs. design variables for $\mathrm{i}=498,359$ and 127 , respectively, e) side view of (a) for nominal tool path, f) side view of (a) for optimal tool path, g) $\theta_{t, i}, \theta_{l, i}, \theta_{t, i}^{*}$ and $\theta_{l, i}^{*}$ along the tool path.

The tool path is designed in such a way that the scallop height, $s_{\mathrm{h}}$, is $0.021 \mathrm{~mm}$ in this operation $\left(s_{h} \simeq s_{s} \sin \left(s_{s} / 2 R\right)\right.$, where $s_{s}=0.5 \mathrm{~mm}$ and is shown in detailed view of Fig. 6a). The axial depth The operation resembles the schematic view of the process in Fig. 7a where small flute's cutting edge engagement would be left after the optimization. The flute's cutting edge engagement, $l_{1}$, map for design variables, tilt and lead angles, are shown in Figs. 7b-d at $i=498,359$ and 127, 
respectively. The grey areas in these figures represent not feasible regions of the design variables due to the tool center engagement with CWE or the cylindrical part engagement of the tool. The colored areas are feasible machining regions. Larger CWEs leads to smaller feasible regions as seen in Figs. $6 \mathrm{~b}-\mathrm{d}$. At $i=498$ where CWE is large, $l_{1}=7.15 \mathrm{~mm}$ and $l_{1}^{*}=0.59 \mathrm{~mm}$ which shows $\sim 92 \%$ reduction in the flute's cutting edge engagement $((7.15-0.59) / 7.15 \times 100=91.75 \%) . l_{1}=6.1$ $\mathrm{mm}$ and $l_{1}^{*}=0.55 \mathrm{~mm}$ at $i=127 ;$ and $l_{1}=3.7 \mathrm{~mm}$ and $l_{1}^{*}=0.52 \mathrm{~mm}$ at $i=359 ;$ with $\sim 91 \%$ and $\sim 86 \%$ reduction in flute's cutting edge engagement length, respectively.

Figs. 7e and $\mathrm{f}$ show the side view of Fig. 7a for nominal and optimal tool paths, respectively. Tool tip's location change is clear in comparison with Figs. 7e and $\mathrm{f}$ while $\mathbf{C T}_{i}$ is kept the same. In addition, the tool tip in some regions of the free form path is in engagement with the workspace, as can be seen in Fig. 7a at $i=498$ and Figs. 7b and e, which is not desired in the ball end milling processes. The optimization problem as a part of its constraints, as described in Section 4.2, approaches a feasible solution where the tool tip is outside of the $\mathrm{CWE}_{i}$, the origin of TCS ${ }^{*}$ in Fig. 7a at $i=498$. Fig. $7 \mathrm{~b}$ shows that the nominal orientation, $\Gamma_{498}$, which is in grey (not feasible region) is adjusted to $\Gamma_{498}^{*}$ with minimum possible $l_{1}$. Fig. $7 \mathrm{~d}$ shows nominal tilt, $\theta_{t, i}$, and lead, $\theta_{l, i}$, angles and optimized tilt, $\theta_{t, i}^{*}$, and lead,$\theta_{l, i}^{*}$, angles along the curve parameter, $u$, of CT ( $\Gamma_{127}=\left\{-45.1^{\circ},-26.5^{\circ}\right\}, \quad \Gamma_{127}^{*}=\left\{0^{\circ},-21.8^{\circ}\right\}, \quad \Gamma_{359}=\left\{-42.2^{\circ},-35.3^{\circ}\right\}, \quad \Gamma_{359}^{*}=\left\{-6.2^{\circ},-31.1^{\circ}\right\}$, $\Gamma_{498}=\left\{-46.1^{\circ},-27.8^{\circ}\right\}$ and $\left.\Gamma_{498}^{*}=\left\{-0.2^{\circ},-15.5^{\circ}\right\}\right)$. The computation time is $\sim 3$ min on a laptop with Corei7-8550U $1.8 \mathrm{GHz}$ (base) and $4 \mathrm{GHz}$ (max turbo) CPU while the computation time is expected to be in the scale of an hour for the mirror method [20] which uses cutting force and surface error prediction iteratively. 
Fig. 8a shows the conducted five-axis machining experiment. The geometric surface errors of the machined parts are measured by a coordinate measuring machine (CMM), as shown in Fig. 8b, along CC (see Fig. 7a). Four parts, I to IV, are machined on the workpiece as shown in Fig. 8b. In order to cancel out other error sources, except tool deflection, in the measured geometric surface errors, reference parts, I and III, are machined on the workpiece. Part I is machined a few times with the same nominal tool path until no material removal is visible. The measured errors on part I originate in other error sources rather than tool deflection (because there was no chip removal after few times down-milling machining operations) such as geometric errors of the machine and tool runout. Part II is machined with the nominal tool path only once. The difference between the measured errors between parts I and II is the surface error due to tool deflection along CC for the nominal tool path which is plotted in Fig. 8c. Part III is machined a few times with the optimized tool path and part IV is machined by the same tool path only once. The difference between the measured surface error between parts III and IV is the surface error of the optimized path as shown in Fig. 8c.

The geometric surface errors for the nominal tool path along the straight section are $\sim 40 \mu \mathrm{m}$. However, the geometric surface errors for the optimized path are $\sim 2 \mu \mathrm{m}, \sim 95 \%$ error reduction $((40-2) / 40 \times 100=95 \%)$, for this section. In the free form section of the nominal tool path, the tool and workpiece are engaged with large CWE, as shown in Fig. 7a at $i=498$, therefore the surface error is as high as $\sim 300 \mu \mathrm{m}$ due to large $l_{1}$. However, the surface error is reduced drastically to $\sim 26 \mu \mathrm{m}$ which indicates $91 \%((300-26) / 300 \times 100=91 \%)$ reduction in geometric surface errors.

Reasons behind the remaining surface error on the workpiece can be traced back to adjusted tool orientation and consequent new trapped flute's cutting edge engagement and tooltip 
locations. As shown in the detailed view of Fig. 7a, the optimization problem reaches to a minimum flute's cutting edge engagement length, $l_{1}^{*}$, which is not zero $\left(l_{1}^{*} s\right.$ along the tool path are $\sim 0.55 \mathrm{~mm}$ ) and leaves small amount of geometric surface errors. As expected, the computed reduction in geometric surface errors (91-95\%) at all computed locations are at the same order as the computed reduction in the flute's cutting edge engagements (86-92\%). In addition, in the free form section of the tool path where CWE is large, the tooltip is in contact with the workpiece where the optimization problem resolved this problem by applying the constraint related to the tooltip expressed in Eq. 23. Since the optimal tooltip is very close to the boundary of CWE, the tip could still be in engagement with the workpiece even using the optimized tool orientation due to the geometrical error of the machine tool or the workpiece or the tool runout. The runout can also cause discrepancies between the actual and calculated minimized flute's cutting edge engagement due to unequal penetration of the flutes to CWE. 
(a)

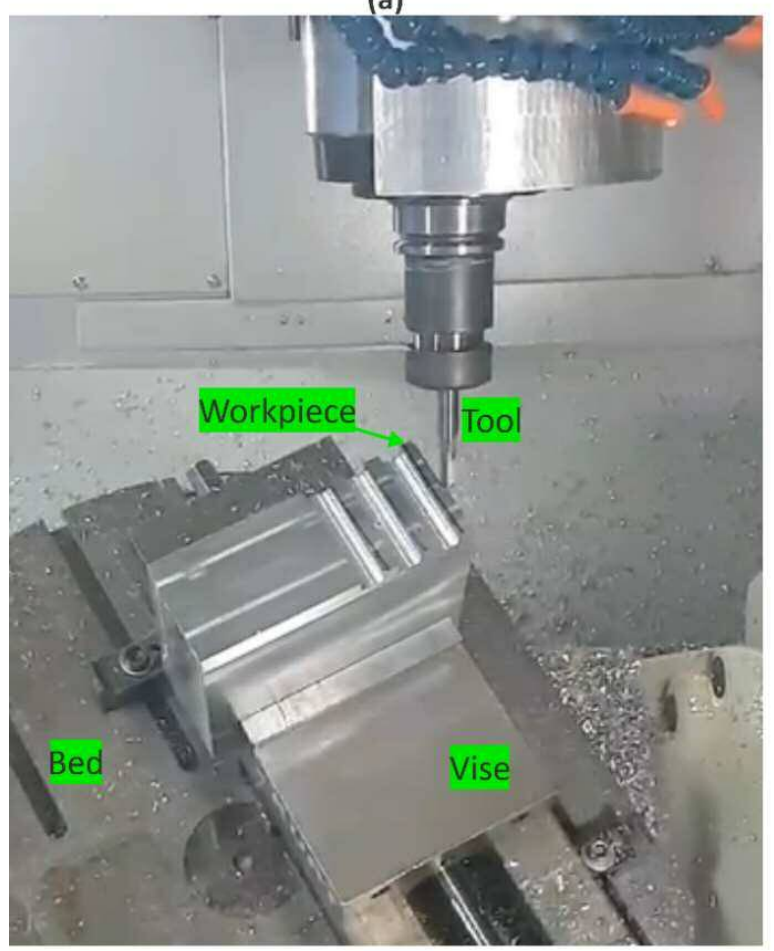

(b)

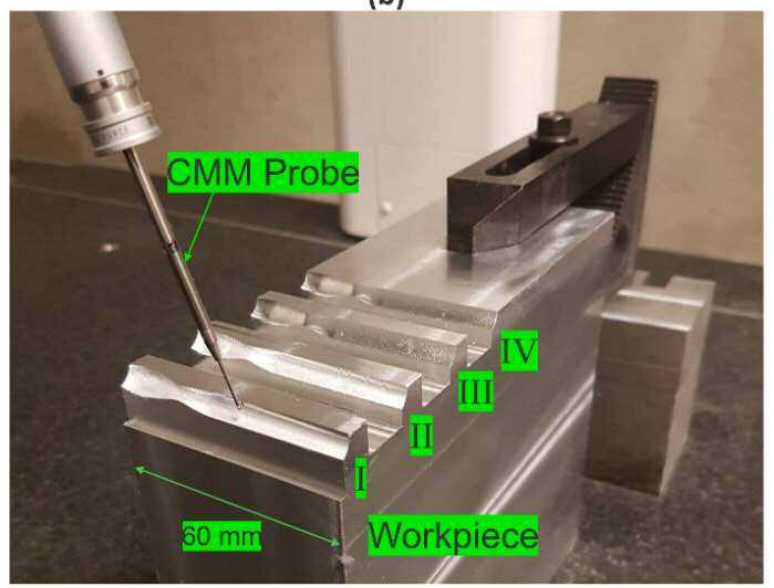

(c)

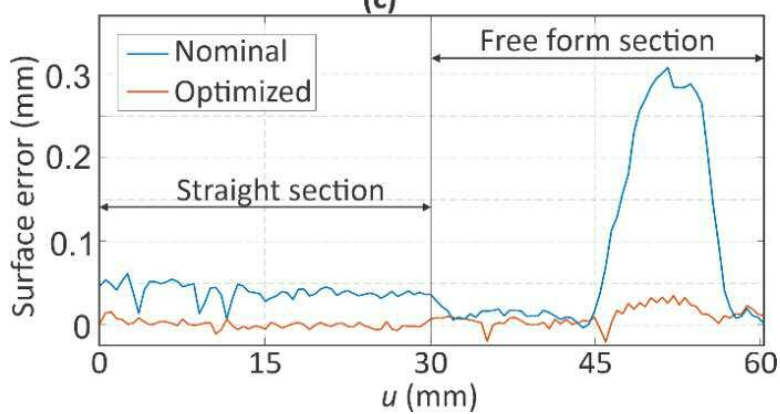

Fig. 8. Experimental validation, a) five-axis machining, b) $\mathrm{CMM}$ measurement of the machined part, c) measured geometric surface errors. 


\section{Conclusion}

The present paper introduces a pure geometric approach to reduce the geometric surface errors in multi-axis ball end milling processes by minimizing the lengths of the flutes' cutting edges engaged with CWE at each cutter location via tool orientation adjustment while keeping the nominal tool center. The proposed method is computationally less expensive in comparison with methods that need to calculate the cutting forces and tool and workpiece deflections to compensate the geometric surface errors. The proposed approach is implemented by constructing an optimization problem with an objective function as the total length of the engaged flutes' cutting edges with CWE. A five-axis ball-end milling test is conducted to validate the method. Drastic surface error reduction, more than $\sim 90 \%$, was observed in the validation experiments.

Initial value selection, especially, for the first $C L$ point, is crucial for the convergence of the optimization problem. Inappropriate selection of the initial guess could lead to optimization divergence. Therefore, a global optimization algorithm should be implemented for the first $\mathrm{CL}$ point. For the rest of the $\mathrm{CL}$ points, since they are very close to each other, the optimization solution for the $\mathrm{CL}_{i-1}$ could be considered as the initial values for $\mathrm{CL}_{i}$ as mentioned in Section 4.3. In the present paper, runout affects have not been taken into consideration. Runout makes each cutting edge geometrically unique and this needs to be incorporated in the geometric model developed in this work. The presented method opens up a new approach in compensating deflection errors in other machining processes with different cutting tools rather than the ball end mills. Also, the tool runout could be integrated with the optimization problem in the objective function. 
Acknowledgment: This research is supported by NSERC - Pratt \& Whitney Canada Industrial Research Chair Grant on Virtual Machining (IRCPJ 260683-12). The support of CANRIMT Strategic Research Network partners Sandvik Coromant, Industrial Technology Research Institute of Taiwan and Boeing Company is greatly acknowledged.

\section{References}

[1] Y. Altintas, P. Kersting, D. Biermann, E. Budak, B. Denkena, and I. Lazoglu, Virtual process systems for part machining operations, CIRP Annals, 63(2) (2014) 585-605, https://doi.org/10.1016/j.cirp.2014.05.007.

[2] N. Wielki, S. Kuschel, J. Sölter, A Comparative Study of the Influence of the Strain-Hardening in Chip Formation Simulations using Different Software Packages, Procedia CIRP, 82 (2019) 4346, https://doi.org/10.1016/j.procir.2019.03.275.

[3] AdvantEgde ${ }^{\mathrm{TM}}$ software, Third Wave Systems, MN, USA. https://www.thirdwavesys.com/advantedge/

[4] Yusuf Altintas, Virtual High Performance Machining, Procedia CIRP, 46 (2016) 72-378, https://doi.org/10.1016/j.procir.2016.04.154.

[5] MACHPRO $^{\text {TM }}$ software, Manufacturing Automation Laboratory, The University of British Columbia, BC, Canada, https://www.malinc.com/products/machpro/. 
[6] D. Umbrello, R. M'Saoubi, J.C. Outeiro, The influence of Johnson-Cook material constants on finite element simulation of machining of AISI 316L steel, International Journal of Machine Tools and Manufacture, 47(3-4) (2007) 462-470,https://doi.org/10.1016/j.ijmachtools.2006.06.006.

[7] Y. Altintas, Manufacturing Automation, Cambridge University Press, 2012, https://doi.org/10.1017/СBO9780511843723.

[8] S. Suh, J. Cho, J. Hascoet, Incorporation of tool deflection in tool path computation: Simulation and analysis, Journal of Manufacturing Systems, 15(3) (1996) 190-199, https://doi.org/10.1016/0278-6125(96)89571-9.

[9] M. Habibi, B. Arezoo, M. Nojedeh, Tool deflection and geometrical error compensation by tool path modification, International Journal of Machine Tools and Manufacture, 51(6) (2011) 439-449, https://doi.org/10.1016/j.ijmachtools.2011.01.009.

[10] M. Soori, B. Arezoo, M. Habibi, Tool Deflection Error of Three-Axis Computer Numerical Control Milling Machines, Monitoring and Minimizing by a Virtual Machining System, ASME. J. Manuf. Sci. Eng., 138(8) (2016) 081005-081005-11. doi:10.1115/1.4032393.

[11] M. Wan, W.H. Zhang, G.H. Qin, Z.P. Wang, Strategies for error prediction and error control in peripheral milling of thin-walled workpiece, International Journal of Machine Tools and Manufacture, 48(12-13) (2008) 1366-1374, https://doi.org/10.1016/j.ijmachtools.2008.05.005.

[12] W. Chen, J. Xue, D. Tang, H. Chen, S. Qu, Deformation prediction and error compensation in multilayer milling processes for thin-walled parts, International Journal of Machine Tools and Manufacture, 49(11) (2009)859-864, https://doi.org/10.1016/j.ijmachtools.2009.05.006. 
[13] W. Ma, G. He, L. Zhu, Tool deflection error compensation in five-axis ball-end milling of sculptured surface, Int J Adv Manuf Technol, 84 (2016) 1421. https://doi.org/10.1007/s00170015-7793-8.

[14] Z.C. Wei, M.J. Wang, W.C. Tang, Form error compensation in ball-end milling of sculptured surface with z-level contouring tool path, Int J Adv Manuf Technol, 67 (2013) 2853. https://doi.org/10.1007/s00170-012-4698-7

[15] T.C. Bera, K.A. Desai, P.V.M. Rao, Error compensation in flexible end milling of tubular geometries, Journal of Materials Processing Technology, 211(1) (2011) 24-34, https://doi.org/10.1016/j.jmatprotec.2010.08.013.

[16] S. Ratchev, S. Liu, W. Huang, A.A. Becker, An advanced FEA based force induced error compensation strategy in milling, International Journal of Machine Tools and Manufacture, 46(5) (2006) 542-551, https://doi.org/10.1016/j.ijmachtools.2005.06.003.

[16] C. Sun, Y. Altintas, Chatter free tool orientations in 5-axis ball-end milling, International Journal of Machine Tools and Manufacture, 106 (2016) 89-97, https://doi.org/10.1016/j.ijmachtools.2016.04.007.

[17] E. Ozturk, L.T. Tunc, E. Budak, Investigation of lead and tilt angle effects in 5-axis ball-end milling processes, International Journal of Machine Tools and Manufacture, 49(14) (2009) 10531062, https://doi.org/10.1016/j.ijmachtools.2009.07.013.

[18] S. Layegh, I. Lazoglu, 3D surface topography analysis in 5-axis ball-end milling, CIRP Annals, 66(1) (2017) 133-136, https://doi.org/10.1016/j.cirp.2017.04.021. 
[19] S. Layegh, I. Yigit, I. Lazoglu, Analysis of tool orientation for 5-axis ball-end milling of flexible parts, CIRP Annals, 64(1) (2015) 97-100, https://doi.org/10.1016/j.cirp.2015.04.067.

[20] M. Habibi , O. Tuysuz , Y. Altintas, Modification of Tool Orientation and Position to Compensate Tool and Part Deflections in Five-Axis Ball End Milling Operations, Journal of Manufacturing Science and Engineering, 141(3) (2019) 031004 (9 pages), https://doi.org/10.1115/1.4042019.

[21] Y. Altintas, O. Tuysuz, M. Habibi, Z. L. Li, Virtual compensation of deflection errors in ball end milling of flexible blades, CIRP Annals, 67-1 (2018) 365-368, https://doi.org/10.1016/j.cirp.2018.03.001.

[22] S. Engin, Y. Altintas, Mechanics and dynamics of general milling cutters. Part I: helical end mills, International Journal of Machine Tools \& Manufacture 41 (2001) 2195-2212, https://doi.org/10.1016/S0890-6955(01)00045-1.

[23] Y. Altintaş, E. Budak, Analytical Prediction of Stability Lobes in Milling, CIRP Annals, Volume 44 (1995) 357-362, https://doi.org/10.1016/S0007-8506(07)62342-7. 